\title{
DETERMINING THE IMPACTS OF FREIGHT TRANSPORT MODE COMBINATIONS ON AIR POLLUTION USING ARTIFICIAL NEURAL NETWORKS
}

\author{
UDC (004.032.26:(504.75.054:614.715))
}

\author{
Nikola Petrović1, Vesna Jovanović1, \\ Marijana Petrović², Boban Nikolić ${ }^{1}$ \\ ${ }^{1}$ University of Niš, Faculty of Mechanical Engineering, Republic of Serbia \\ ${ }^{2}$ University of Belgrade, Faculty of Transport and Traffic Engineering, \\ Republic of Serbia
}

\begin{abstract}
Transport is one of the largest emitters of harmful substances that affect air quality. Each combination of freight transport modes has a different volume and at the same time has a differentiated negative impact on air quality. That is why the European Union has been making special efforts for many years to create and implement strategies aimed at improving air quality. The main goal of this paper is to present a methodology that enables quantification and analysis of the impact of each freight transport mode combination on air quality using feed-forward neural networks. The developed model uses the parameters of the EU member states in the period from 2000 to 2014. In addition to the scientific and practical contribution, the development of the model provides a good basis for the universal platform formation in order to create and develop strategies, i.e. measures to improve air quality on a global level.
\end{abstract}

Key words: Freight transport, air quality, Extreme Learning Machine

\section{INTRODUCTION}

Air pollution, i.e. reduction of air quality, is one of the types of environmental degradation. Since there is a negative impact on the environment, climate, flora and fauna, the pollutants have the same negative impact on human health. Caused by transport activities, air pollution (greenhouse gases $(\mathrm{GHG})$, carbon dioxide $\left(\mathrm{CO}_{2}\right)$, nitrogen oxides $(\mathrm{NOx})$, particulate matter $\left(\mathrm{PM}_{2.5}\right)$, sulfur dioxide $\left(\mathrm{SO}_{2}\right)$, etc.) leads to cardiovascular and respiratory diseases and material damage and losses due to reduced grain yields and impacts on biodiversity and ecosystems.

Received November 16, 2020

Corresponding author: Nikola S. Petrović

Faculty of Mechanical Engineering, Aleksandra Medvedeva 14, 18000 Niš, Republic of Serbia

E-mail: petrovic.nikola@masfak.ni.ac.rs 
The rapid development of the transport and the related environmental problems pertaining to air pollution and GHG emissions have raised the global concern [1]. Following the power generation sector, the global transport sector is the second largest sector generating GHG emissions causing $23 \%$ of total GHG emissions worldwide [2]. Transport is responsible for nearly one quarter of global energy related carbon dioxide emissions with $75 \%$ of these emissions related to road transport energy use [3]. GHG emissions account for $70 \%$ of the total GHG emissions from humans with the major emission sources from fossil fuels of energy supply and transportation [4].

Transport has become more energy efficient, but in the European Union $96 \%$ of transport energy is still based on consumption of oil and its products [5]. The EU has conducted an analysis which demonstrated the need for a drastic reduction in emissions by 2050 for $80-95 \%$ below the level in 1990. The analysis shows that a $60 \%$ reduction in GHG emissions is needed by 2050 compared to 1990 in the transport sector which is a significant and still growing source of GHG emissions. According to the White Paper, the target for transport by 2030 will be to reduce GHG emissions by about $20 \%$ below its level in 2008 [5].

New transport patterns must emerge, according to which larger volumes of cargo are carried to their destination with the most efficient combination of transport modes. Options for eliminating harmful emissions from road vehicles are limited and freight multimodality (intermodality) must become economically attractive. Effective cooperation of transport modes is needed. Individual transport is preferably used for final destinations performed with clean vehicles. By optimizing the performance of multimodal transport technologies, which means greater use of more energy efficient transport modes, $30 \%$ of road freight transport should be directed to other modes such as rail and water transport by 2030 , and more than $50 \%$ by 2050 , all airports should be connected by rail and it must be ensured that all seaports are sufficiently connected with rail for the freight transport and where possible, by inland waterways [5].

In the EU, $\mathrm{CO}_{2}$ emissions from maritime transport should be reduced by $40 \%$ by 2050 compared to the level in 2005 [5]. Inland waterways, which represent an untapped potential, must play an increasing role, especially in connecting European seas. The EU aviation industry should become a leader in the use of low-carbon fuels. Road freight transport causes about $7 \%$ of total world carbon emissions. With the right incentives, energy savings and emission reductions can be achieved by combining them with the rail or water transport, which are far more efficient than the road transport.

Due to the decades-long increase in emissions of harmful substances caused by transport activities, in the EU special efforts have been made for many years to assess possible scenarios for the development of freight transport, as well as for the formation and implementation of strategies to reduce the negative impacts of freight transport on the air quality.

Today, due to advances in technology, data is being generated at an incredible rate, leading to data sets of enormous dimensions. That is why it is important to have efficient computational methods and algorithms that can deal with such large data sets, so that they can be analyzed within a reasonable time frame.

Artificial neural networks (ANNs) are a relatively new concept for data analysis and a completely different approach from that used in multivariate methods. Instead of conceptualizing the problem in a mathematical form, neural networks use the principles of the human brain and its structure to develop a data processing strategy. The most important property of neural networks is the ability to approximate an arbitrary nonlinear 
function with the desired accuracy. This makes neural networks suitable for identifying and managing nonlinear processes.

Learning time is an important factor in modeling computational intelligence algorithms for processes of classification, prediction, etc. One of the biggest disadvantages of classical ANN learning is the excessively long training time which was the main obstacle to the more extensive use of ANN. There is a number of algorithms for learning ANN, such as Back Propagation method, Support Vector Machine, Hidden Markov Model, etc. One particular approach has become popular with Artificial Neural Networks in recent years, the Extreme Learning Machine (ELM) method [6, 7], which uses randomization in its hidden layer and with the help of which it is possible to effectively train network.

State authorities, regulatory agencies and other institutions adopt and implement measures to improve air quality. Taking into account the dynamic and heterogeneous composition of the air, controlling and monitoring air degradation is a major challenge for scientists, researchers and transport policy makers.

This paper is organized as follows. In Section 2, based on searches in the Scopus and Science Direct databases, a review of the relevant literature is given. To create ANN model, it is necessary to define input and output parameters (variables) in order to notice the connections between them and they are given in Section 3. The next section provides an overview of the developed ANN model, a case study based on current data from EU Member States over a multi-year period and a discussion of the results. The concluding remarks are given in the last Section.

\section{LITERATURE REVIEW}

The rapid pace of developments in Artificial Intelligence (AI) is providing unprecedented opportunities to enhance the performance of the transport sector. The application of $\mathrm{AI}$ in the transport field is aimed at overcoming the challenges of an increasing travel demand, pollutant emissions, safety concerns, and environmental degradation.

Rusul Abduljabbar et al provide an overview of the AI techniques applied worldwide to address transportation problems and concludes by addressing the challenges and limitations of AI applications in transport [8].

Lynn H Kaack et al introduce five general strategies for decarbonizing freight transportation, and then focus on the literature and data relevant to estimating the global decarbonization potential through a modal shift [9]. Authors compare the freight activity (in tonne-km) by mode for every country where data are available and also describe major intraregional freight corridors, their modal structure, and their infrastructure needs. Most countries are experiencing a strong growth in road freight and a shift from rail to road. The modal shift can be promoted by policies targeting infrastructure investments and internalizing external costs of road freight, but authors find that not many countries have such policies in place. Also they identify research needs for decarbonizing the freight transportation sector both through improvements in the efficiency of individual modes and through new physical and institutional infrastructure that can support the modal shift [9].

Considering the environmental awakenings at the global level the distribution companies must start to take measures to limit their impacts. In paper [10] authors create a multi-criteria decision support system taking into account the economic, environmental and social criteria in an intermodal transport system. Research shows how a judicious choice of path and transport 
mode in an intermodal transportation system can reduce the emissions of greenhouse gases and the energy consumption; in other words, how the route and transport mode selections can help us reduce the environmental impacts.

The ANN methodology was used in [11] to analyze the impact of population growth in different areas on carbon dioxide emissions. After that, an analysis was conducted to see how transport affects the quality of the environment. The results showed that urban population growth has the greatest impact on carbon dioxide emissions. The paper uses the Extreme learning machine (ELM) method for Single-hidden layer feedforward neural networks (SLFN), which allows good generalization of performance at extreme learning speeds.

Ćirić et al compares different computational intelligence methodologies based on artificial neural networks used for forecasting an air quality parameter - the $\mathrm{CO}_{2}$ emission, in the city of Niš. Based on experimental data, in this paper authors developed different soft computing estimators, such as feed forward neural network, recurrent neural network, and hybrid neuro-fuzzy estimator of $\mathrm{CO}_{2}$ emission levels [12].

In paper [13] the ANN model for the prediction of passenger car fuel consumption in the City of Niš was developed based on experimentally measured data recorded through onboard diagnostics equipment. The fuel consumption of passenger cars is in direct relationship with reduction of $\mathrm{CO}_{2}$ emission. A comprehensive preliminary investigation revealed that a single hidden layer ANN model having ten neurons can be efficiently trained with Levenberg-Marquardt algorithm to provide satisfactory prediction accuracy [13].

Finally, the authors in [14] gave an overview of the basic principles of machine learning techniques, among which the ELM method was observed. The research includes 38 relevant studies in the field of environmental science and engineering that have applied machine learning techniques over the last 6 years.

\section{INPUT DATA}

Modeling the impact of transport mode combinations on the air quality requires appropriate information base - indicators and statistical data. The quantification of the factors that impact on air pollution and air quality is conditioned by the availability of data on air pollution.

The first step in impacts modeling with the ANN methodology is to define the input and output parameters (variables) of the model in order to observe the regularities and connections between them. Data for the analysis were collected from the website of the European Commission for EU countries in the period from 2000 to 2014 [15, 16]. In the process of collecting, the problem of incomplete data arose and an important advantage of artificial neural networks was used, which can use incomplete data in its work.

As input parameters, tonne kilometers were used, generated by: road, rail, air, marine transport and inland waterways (Fig. 1). Emissions of greenhouse gases (GHG), carbon dioxide $\left(\mathrm{CO}_{2}\right)$, nitrogen oxides $(\mathrm{NOx})$, particulate matter $\left(\mathrm{PM}_{2.5}\right)$ and sulfur dioxide $\left(\mathrm{SO}_{2}\right)$, respectively, were analyzed as output parameters. 


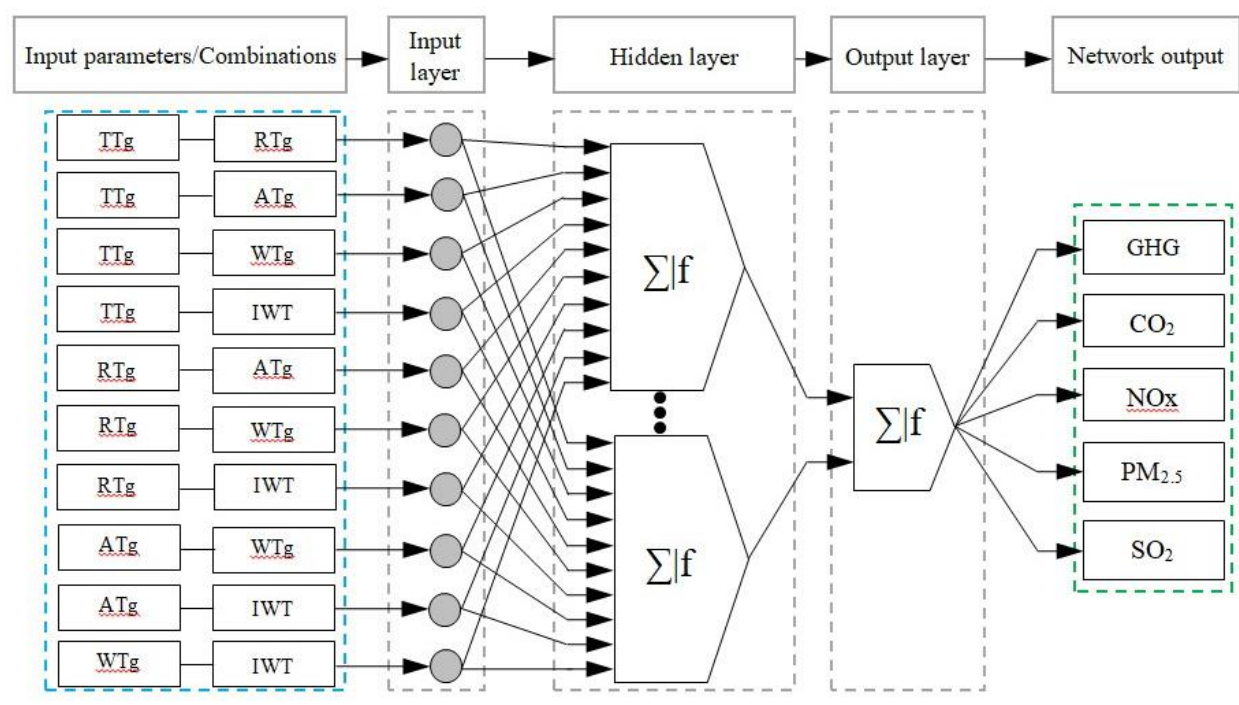

Fig. 1 ANN model for determining the impacts of freight transport mode combinations on air pollution

\section{THE APPROACH, CASE STUdY AND RESUlTs Discussions}

The developed ANN model represents a three-layer feed-forward neural network, which consists of one input, one hidden and one output layer (Fig. 1). The input layer consists of ten neurons or ten different inputs to the neural network i.e. ten different combinations of freight transport modes. The output layer of the neural network always consists of one neuron, whose output for each combination of input variables is one of the emissions originating from transport, respectively greenhouse gases $(\mathrm{GHG})$, carbon dioxide $\left(\mathrm{CO}_{2}\right)$, nitrogen oxides (NOx), particulate matter $\left(\mathrm{PM}_{2.5}\right)$ and sulfur dioxide $\left(\mathrm{SO}_{2}\right)$. The sigmoid (logistic) function was used as the activation function for the output layer, while the linear (purelin) function was used for the hidden layer. The choice of this network was made on the basis of the ability to approximate any arbitrary continuous function from several real variables.

All data for EU countries are divided into groups of 50\% for training and 50\% for testing. It is important that these two groups of data are the same for the selecting process of the most influential input parameters. In testing the Root Mean Square Error (RMSE) error is used to monitor and control the flow of the regression between data sets for training and testing [17].

In a defined ANN model for training the neural network was used an ELM method [6, 7] in which it is not necessary to adjust the input weight coefficients and influences (biases) of the hidden layer. The adopted learning algorithm independently adjusts the parameters of the neural network in order to find their right combination with which the neural network approximates the nonlinear function with high quality [18]. Networks are trained for input data so that they determine the specific RMSE error of each input to a specific output. The neural network training process needs to be stopped when the RMSE testing error starts to show its rapid growth in relation to the RMSE training error, i.e. a deviation occurs between the data sets for training and testing. The input variable with the 
obtained smallest RMSE training error has the greatest influence on the observed output variable and vice versa, i.e. the input variable with the largest RMSE error has the smallest influence on the adopted output variable. All input and output variables are modeled within the Matlab software. The obtained values of the smallest RMSE training error are marked with Underline while the highest values are marked with Italic.

Table 1 Impacts of combinations of freight transport modes on air pollution [16]

\begin{tabular}{|c|c|c|c|c|c|c|c|c|c|c|c|}
\hline \multirow{3}{*}{ Combi } & & \multicolumn{10}{|c|}{ RMSE } \\
\hline & lations & \multirow{2}{*}{\multicolumn{2}{|c|}{$\begin{array}{c}\text { GHG } \\
\text { training testing }\end{array}$}} & \multicolumn{2}{|c|}{$\mathrm{CO}_{2}$} & \multicolumn{2}{|c|}{ NOx } & \multicolumn{2}{|c|}{$\mathrm{PM}_{2.5}$} & \multicolumn{2}{|c|}{$\mathrm{SO}_{2}$} \\
\hline & & & & raining & testing & training & testing & training & testing & training & testing \\
\hline TTg & $\mathrm{RTg}$ & 17,377 & 247,552 & $\underline{2,754}$ & 67,386 & $\underline{2,322}$ & 123,801 & 8207,515 & 11396,324 & 4512,169 & 13579,315 \\
\hline TTg & ATg & $\underline{7,401}$ & 1589,953 & 3,515 & 624,935 & 3,247 & 251,238 & 8238,254 & 10582,030 & $\underline{251,711}$ & 28526,140 \\
\hline TTg & WTg & 9,932 & 376,654 & 2,997 & 678,003 & 2,558 & 157,932 & 8213,322 & 10987,332 & 987,776 & 2197,901 \\
\hline TTg & IWT & 11,752 & 298,998 & 3,323 & 576,776 & 2,985 & 193,731 & 8221,991 & 11239,999 & 2143,554 & 2431,765 \\
\hline RTg & ATg & 12,270 & 465,643 & 6,487 & 319,692 & 10,994 & 259,302 & $\underline{3555,404}$ & 8031,877 & 713,342 & 27127,227 \\
\hline $\mathrm{RTg}$ & WTg & 12,654 & 487,901 & 7,912 & 412,918 & 11,441 & 276,901 & 3711,331 & 8089,001 & 715,413 & 29811,887 \\
\hline $\mathrm{RTg}$ & IWT & 13,213 & 491,321 & 8,233 & 441,901 & 11,988 & 299,811 & 3901,221 & 8978,221 & 717,004 & 29977,776 \\
\hline $\mathrm{ATg}$ & WTg & 17,205 & 49,221 & 6,570 & 156,706 & 9,992 & 39,997 & 6997,991 & 108245,766 & 671,998 & 34398,667 \\
\hline $\mathrm{ATg}$ & IWT & 16,947 & 48,147 & 6,895 & 254,458 & 8,876 & 124,529 & 6285,358 & 107572,292 & 634,742 & 33965,417 \\
\hline WTg & IWT & 16,901 & 47,361 & 5,760 & 132,775 & 9,141 & 37,113 & 6975,554 & 101051,776 & 576,322 & 33374,774 \\
\hline
\end{tabular}

Based on the obtained results, it can be seen that the combinations of input parameters TTg (Road freight transport) and RTg (Rail freight transport), TTg (Road freight transport) and ATg (Air freight transport) as well as RTg (Rail freight transport) and ATg (Air freight transport) have the smallest RMSE training error and therefore have the greatest impacts, respectively, on emissions of carbon dioxide $\left(\mathrm{CO}_{2}\right)$ and nitrogen oxides (NOx), greenhouse gases (GHG) and sulfur dioxide $\left(\mathrm{SO}_{2}\right)$ as well as particulate matter $\left(\mathrm{PM}_{2.5}\right)$.

Combinations of input parameters TTg (Road freight transport) and RTg (Rail freight transport), TTg (Road freight transport) and ATg (Air freight transport) as well as RTg (Rail freight transport) and IWT (Inland waterway freight transport) have the largest RMSE error and therefore have the smallest impacts, respectively, on emissions of greenhouse gases $(\mathrm{GHG})$ and sulfur dioxide $\left(\mathrm{SO}_{2}\right)$, particulate matter $\left(\mathrm{PM}_{2.5}\right)$ as well as carbon dioxide $\left(\mathrm{CO}_{2}\right)$ and nitrogen oxides (NOx).

The combination of RTg (Rail freight transport) and IWT (Inland waterway freight transport) is optimal for the freight transport in order to achieve the lowest emission of carbon dioxide and nitrogen oxides. Also, it is necessary to avoid the following combination of transport modes, RTg (Rail freight transport) and ATg (Air freight transport), due to its greatest impact on the emission of particulate matter. 


\section{CONCLUSION}

Transport is an economic activity that exhibiths the largest increase in environmental degradation and air quality. The conducted research refers to the determining and analysis of combinations freight transport modes on air quality using feed-forward neural networks. The modeling was performed on the basis of input and output parameters in order to determine the impacts of combinations of freight transport modes on air pollution in the period from 2000 to 2014 for the countries of the European Union. As input parameters were used tonne kilometers generated by road, rail, air, marine transport and inland waterways. Emissions of greenhouse gases, carbon dioxide, nitrogen oxides, particulate matter and sulfur dioxide, respectively, were analyzed as output parameters.

Based on the obtained results, it can be seen that the combinations of input parameters TTg (Road freight transport) and RTg (Rail freight transport), TTg (Road freight transport) and ATg (Air freight transport) as well as RTg (Rail freight transport) and ATg (Air freight transport) have the greatest impacts, respectively, on emissions of carbon dioxide and nitrogen oxides, greenhouse gases and sulfur dioxide as well as particulate matter.

Combinations of input parameters TTg (Road freight transport) and RTg (Rail freight transport), TTg (Road freight transport) and ATg (Air freight transport) as well as RTg (Rail freight transport) and IWT (Inland waterway freight transport) have the smallest impacts, respectively, on emissions greenhouse gases and sulfur dioxide, particulate matter as well as carbon dioxide and nitrogen oxides.

The combination of RTg (Rail freight transport) and IWT (Inland waterway freight transport) is optimal for the freight transport in order to achieve the lowest emission of carbon dioxide and nitrogen oxides. Also, it is necessary to avoid the combination RTg (Rail freight transport) and ATg (Air freight transport), due to its greatest impact on the emission of particulate matter.

New technologies for vehicles and transport management will be keys to reducing transport emissions in the EU, as in the rest of the world. Delayed action and the shy introduction of new technologies would condemn the EU transport industry to decline irreversibly. In Europe, there is a tendency to redirect the flow of goods from road to some other transport mode. The European Union is trying to promote multimodal (intermodal) alternatives by investing in railways and its infrastructure, while increasing the fee for the use of roads.

In addition to encouraging combinations of alternative freight transport solutions, it is necessary to improve truck efficiency, through the development and acceptance of new engines and cleaner fuels, the use of intelligent transport systems and additional measures to improve market mechanisms.

Although in theory the ELM method has proven to be a universal approximator in practice it is significantly important how many samples are available for training; whether there are elements in the data that do not belong to others; and which variables are used as inputs. Therefore, it is necessary to pay attention to get a robust and precise model and prevent excessive errors.

Acknowledgement: This research was financially supported by the Ministry of Education, Science and Technological Development of the Republic of Serbia. 


\section{REFERENCES}

[1] T. Yihui, Z. Qinghua, L. Kee-Hung, Y.H.L. Venus, "Analysis of greenhouse gas emissions of freight transport sector in China", Journal of Transport Geography, vol. 40, pp. 43-52, 2014. [Online]. Available: https://doi.org/ 10.1016/j.jtrangeo.2014.05.003

[2] IEA (International Energy Agency), $\mathrm{CO}_{2}$ Emissions from Fuel Combustion, Paris, France, 2012

[3] A. Ajanovic, C. Dahl, L. Schipper, "Modelling transport (energy) demand and policies - An introduction", Energy Policy, vol. 41, iii-xiv, 2012. [Online]. Available: doi: 10.1016/j.enpol.2011.12.033

[4] UN (United Nations), "Urbanization and development: Emerging Futures", World Cities Report 2016, United Nations Human Settlements Programme, 2016. from: http://wcr.unhabitat.org .

[5] European Commission, "White paper on transport: Roadmap to a single European Transport area — towards a competitive and resource-efficient transport system", Publications Office of the European Union, 2011.

[6] H. Guang-Bin, Z. Qin-Yu, S. Chee-Kheong, "Extreme Learning Machine: A New Learning Scheme of Feedforward Neural Networks", International Joint Conference on Neural Networks, vol. 2, pp: 985-990, 2004. [Online]. Available: doi: 10.1109/ijenn.2004.1380068

[7] W. Dianhui, H. Guang-Bin, "Protein Sequence Classification Using Extreme Learning Machine", in Proceedings of International Joint Conference on Neural Networks, vol. 3, pp: 1406- 1411, 2005. [Online]. Available: doi: 10.1155/2014/103054

[8] R. Abduljabbar, H. Dia , S. Liyanage, S. A. Bagloee, "Applications of Artificial Intelligence in Transport: An Overview", Sustainability, 11, 189, 2019. [Online]. Available: doi: 10.1049/ip-its:20060014

[9] L. H Kaack, P. Vaishnav, M. G. Morgan, I. L. Azevedo, S. Rai, "Decarbonizing intraregional freight systems with a focus on modal shift", Environ. Res. Lett. 13, 2018. [Online]. Available: doi: 10.1088/1748-9326/aad56c

[10] M. Sawadogo, D. Anciaux, "Reducing the environmental impacts of intermodal transportation: a multi-criteria analysis based on ELECTRE and AHP methods", 3rd International Conference on Information Systems, Logistics and Supply Chain Creating value through green supply chains, Casablanca, Morocco, pp. 224., 2010.

[11] N. Petrović, N. Bojović, J. Petrović, "Appraisal of urbanization and traffic on environmental quality", Journal of $\mathrm{CO}_{2}$ Utilization, vol. 16, pp. 428-430, 2016. [Online]. Available: https://doi.org/10.1016/j.jcou.2016.10.010

[12] I. Ćirić, Ž. Čojbašić, V. Nikolić, P. Živković, M. Tomić, Air quality estimation by computational intelligence methodologies, Thermal Science, Vol. 16, Suppl. 2, pp. S493-S504, 2012. [Online]. Available: doi: 10.2298/ tsci120503186c

[13] B. Predić, M. Madić, M. Roganović, M. Kovačević, D. Stojanović, Prediction of passenger car fuel consumption using artificial neural network: a case study in the city of Niš, Facta Universitatis, Series: Automatic Control and Robotics, vol. 15, no. 2, pp. 105-116, 2016.

[14] A. Masih, "Machine learning algorithms in air quality modeling", Global Journal of Environmental Science and Management, vol. 5, no. 4, pp. 515-534, 2019. [Online]. Available: doi: 10.22034/gjesm.2019.04.10

[15] https://ec.europa.eu/transport/facts-fundings/statistics

[16] N. Petrović, Managing the impacts of urbanization and transport modes on the environment quality, Doctoral dissertation, University of Belgrade, Faculty of transport and traffic engineering, 2018.

[17] B. Batinić, Model for prediction of the quantity of packaging and biodegradable waste using neural networks, Doctoral dissertation, University of Novi Sad, Faculty of Technical Sciences, 2015.

[18] G. B. Huang, Q. Z. Y. Zhu, Ch. K. Siew, "Extreme Learning Machine: Theory and Applications", Neurocomputing, vol. 70, pp. 489-501, 2006. [Online]. Available: https://doi.org/10.1016/j.neucom.2005.12.126 